\title{
The Use of Cannabis for Medical Purposes in the Arab World
}

\author{
Bader H. Shirah ${ }^{\mathrm{a}}$ Mohammed M. Ahmed ${ }^{\mathrm{b}}$ \\ aKing Abdullah International Medical Research Centre/King Saud bin Abdulaziz University for Health Sciences, \\ Jeddah, Saudi Arabia; ' ${ }^{\prime}$ lbn Sina National College, Jeddah, Saudi Arabia
}

\section{Keywords}

Cannabis · Medical marijuana $\cdot$ Arab world

\begin{abstract}
The legal landscape of cannabis (marijuana) has dramatically changed over the past few years in several countries worldwide. Many patients now have legal access to products derived from cannabis. In the Middle East, Lebanon became the first Arab country to legalize cannabis for medical and industrial use recently in 2020. Other Middle Eastern and Arab countries continue to completely ban the use of cannabis and products derived from cannabis. This article is a call to conduct medical research in the use of cannabis for medical purposes to determine the suitability and need for this substance in the Arab world. Based on these studies, evidence-based recommendations can be made to the highest authorities in the Arab countries for legalization or continued prohibition. As the international use of cannabis is increasing, the Arab countries may consider legalization of the substance to cover the unmet medical need and offer an additional treatment option for certain conditions.
\end{abstract}

(c) 2020 The Author(s)

Published by S. Karger AG, Basel

karger@karger.com

www.karger.com/mca

Karger

GOPEN ACCESS
(C) 2020 The Author(s)

Published by S. Karger AG, Basel

This is an Open Access article licensed under the Creative Commons Attribution-NonCommercial-4.0 International License (CC BY-NC) (http://www.karger.com/Services/OpenAccessLicense), applicable to the online version of the article only. Usage and distribution for commercial purposes requires written permission.
Cannabis is a plant that has been grown for centuries. It contains chemicals known as cannabinoids. The two most widely studied chemicals are tetrahydrocannabinol (THC) and cannabidiol (CBD). THC is psychoactive and intoxicating, while CBD is mildly psychoactive but not intoxicating [1]. Cannabis, also known as medical marijuana, has been widely studied worldwide and is gaining increasing popularity and acceptance globally [2].

The legal landscape of cannabis (marijuana) has dramatically changed over the past few years in several countries worldwide. Many patients now have legal access to products derived from cannabis. These products have been studied in a wide range of medical disorders. More than 20 countries around the world have legalized the medical use of cannabis. In the USA, over 30 states have legalized medical use of cannabis, and more than 10 states allow for recreational use [3]. In the Middle East, Lebanon became the first Arab country to legalize cannabis for medical and industrial use recently in 2020. Other Middle Eastern and Arab countries continue to completely ban the use of cannabis and products derived from cannabis [4].

Islam forbids the use of illicit drugs since they are highly deleterious. The recreational use of cannabis and any 
narcotic drug is religiously prohibited in Islam. However, it allows the use of some narcotic drugs such as opioids (e.g., morphine and tramadol), which are more dangerous than cannabis, in some medical conditions, especially in anesthesia and pain management. The same rule is applied for cannabis when used for medical purposes as it becomes a legitimate medicine rather than an illicit drug. There is no objection to the use of cannabis or cannabis-derived substances for medical purposes, provided that the treatment and the eventual recovery are dependent on their use and being prescribed by a trustworthy physician. The Islam rule says, "Necessity knows no law" [5].

Current evidence suggests that cannabis works by interacting with the complex system in the human body known as the endocannabinoid system. The diverse and powerful effects of cannabis are due to binding with the endogenous cannabinoid receptors, which are located in the brain, muscles, fat, and gastrointestinal tract. On ingestion of a plant that contains THC and CBD, which are similar in molecular shape to endocannabinoids, these molecules fit into the same receptors and trigger a reaction [6]. The endocannabinoid system can regulate pain, mood, emotions, stress response, appetite, digestive motility, and the immune system [7]. THC is mainly used for pain relief, while CBD reduces seizures and inflammation. The conditions that may be improved by cannabis include inflammatory bowel disease (IBD), multiple sclerosis, neuropathic pain, chemotherapy-related nausea and vomiting, pediatric seizure disorder, and more [8].

In the Middle East and Arab countries, there are several limitations in this field, including the lack of research about the medical use of cannabis, the legal and religious ban of its use, and the lack of financial support to conduct research about cannabis. More studies are needed to have evidence to use cannabis for medical conditions in the Arab population. It remains unclear how, why, and what characteristics and needs are unique to the Arab world, and only more research can answer these questions. Suggested research ideas include cross-sectional studies measuring the perception of both the physicians and the general population toward the use of cannabis for medical purposes, review articles on the medical uses and importance of cannabis to cover the unmet needs, and clinical trials to examine the benefits of cannabis in selected medical conditions. Other research ideas and types of studies can also be performed, such as reverse-translation studies (bedside-to-benchtop research), which begin with actual, real-life patient experiences in the clinic, or during a clin- ical trial, and works backward to uncover the mechanistic basis. In addition, comparative studies may also be an attractive option (i.e., IBD, which also occurs in veterinary patients like colic in horses and IBD in pets). Conducting such research is extremely important as an initial step toward the possible legalization of medicinal/clinical/research use of cannabis in the Arab world. Having robust data generated through high-quality research would support government funding and further advances in the field. This is especially important to determine why cannabis is important specifically to Arab countries and if there are diseases in Arab countries with high prevalence and incidence rate that novel research in cannabinoids may address.

In conclusion, this article is a call to conduct medical research in the use of cannabis for medical purposes to determine the suitability and need for this substance in the Arab world. Based on these studies, evidence-based recommendations can be made to the highest authorities in the Arab countries for legalization or continued prohibition. As the international use of cannabis is increasing, the Arab countries may consider legalization of the substance to cover the unmet medical need and offer an additional treatment option for certain conditions.

\section{Statement of Ethics}

Not required.

\section{Conflict of Interest Statement}

The authors declare that they have no conflicts of interest.

\section{Funding Sources}

The authors did not receive any funding.

\section{Author Contributions}

Both authors contributed equally to this study. 


\section{References}

1 Sheikh NK, Dua A. Cannabinoids. [Updated 2020 Apr 7]. In: StatPearls [Internet]. Treasure Island, FL: StatPearls Publishing; 2020 Jan. Available from: https://www.ncbi.nlm. nih.gov/books/NBK556062/.

2 Hill KP. Medical cannabis. JAMA. 2020; 323(6):580.

3 Levinsohn EA, Hill KP. Clinical uses of cannabis and cannabinoids in the United States. J Neurol Sci. 2020;411:116717.
4 Jaffal LH, Lahoud N, Zein S, Awada S, Khachman D. Lebanese pharmacists' knowledge and attitude toward cannabis medical use legality. DSAHMJ. 2020;2(3):106-14.

5 Robinson D, Ritter S, Zadik-Weiss L, Ounallah-Saad H, Abu-Ahmad N, Kashkoosh R, et al. Bridging the accessibility gap of cannabinoid medicine and arabic culture. Rambam Maimonides Med J. 2020;11(1):e0010.

6 Schurman LD, Lu D, Kendall DA, Howlett AC, Lichtman AH. Molecular mechanism and cannabinoid pharmacology. Handb Exp Pharmacol. 2020;258:323-53.
7 Almogi-Hazan O, Or R. Cannabis, the endocannabinoid system and immunity-the journey from the bedside to the bench and back. Int J Mol Sci. 2020;21(12):4448.

8 Montero-Oleas N, Arevalo-Rodriguez I, Nuñez-González S, Viteri-García A, SimancasRacines D. Therapeutic use of cannabis and cannabinoids: an evidence mapping and appraisal of systematic reviews. BMC Complement Med Ther. 2020;20(1):12. 